This article was downloaded by: [University College London]

On: 28 July 2014, At: 07:31

Publisher: Routledge

Informa Ltd Registered in England and Wales Registered Number: 1072954 Registered office: Mortimer House, 37-41 Mortimer Street, London W1T 3J H, UK

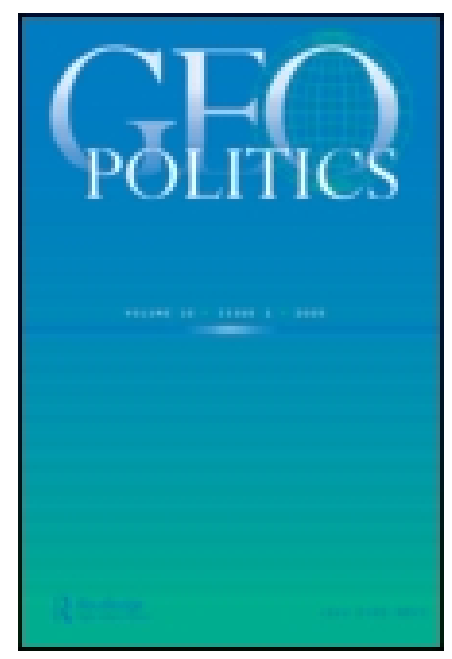

\title{
Geopolitics
}

Publication details, including instructions for authors and subscription information:

http:// www.tandfonline.com/loi/ fgeo20

\section{Humour at the Model United Nations: The Role of Laughter in Constituting Geopolitical Assemblages}

\author{
J ason Dittmer ${ }^{\text {a }}$ \\ a Department of Geography, University College London, UK \\ Published online: 23 May 2013.
}

To cite this article: J ason Dittmer (2013) Humour at the Model United Nations: The Role of Laughter in Constituting Geopolitical Assemblages, Geopolitics, 18:3, 493-513, DOI: 10.1080/ 14650045.2012.742066

To link to this article: http:// dx. doi.org/ 10.1080/ 14650045.2012.742066

\section{PLEASE SCROLL DOWN FOR ARTICLE}

Taylor \& Francis makes every effort to ensure the accuracy of all the information (the "Content") contained in the publications on our platform. Taylor \& Francis, our agents, and our licensors make no representations or warranties whatsoever as to the accuracy, completeness, or suitability for any purpose of the Content. Versions of published Taylor \& Francis and Routledge Open articles and Taylor \& Francis and Routledge Open Select articles posted to institutional or subject repositories or any other third-party website are without warranty from Taylor \& Francis of any kind, either expressed or implied, including, but not limited to, warranties of merchantability, fitness for a particular purpose, or noninfringement. Any opinions and views expressed in this article are the opinions and views of the authors, and are not the views of or endorsed by Taylor \& Francis. The accuracy of the Content should not be relied upon and should be independently verified with primary sources of information. Taylor \& Francis shall not be liable for any losses, actions, claims, proceedings, demands, costs, expenses, damages, and other liabilities whatsoever or howsoever caused arising directly or indirectly in connection with, in relation to or arising out of the use of the Content.

This article may be used for research, teaching, and private study purposes. Terms $\&$ Conditions of access and use can be found at http://www.tandfonline.com/page/termsand-conditions 
It is essential that you check the license status of any given Open and Open Select article to confirm conditions of access and use. 


\title{
Humour at the Model United Nations: The Role of Laughter in Constituting Geopolitical Assemblages
}

\author{
JASON DITTMER \\ Department of Geography, University College London, UK
}

\begin{abstract}
Model United Nations (MUN) is a simulation in which students take on the roles of ambassadors to the United Nations, engaging in debate on 'real' issues from the perspective of their assumed national identities. This paper, based on a year of ethnography and interviews of a college-level MUN team, examines the role of bumour in producing particular geopolitical imaginations among those participating and also in producing the MUN assemblage itself. Key here is the circulation of affects among participants' bodies, producing an orientation among them that facilitates debate and consensus-building. This finding is seen as a corrective to past work on geopolitics and humour, which has tended to emphasise irony and satire, as well as mass-mediated humor.
\end{abstract}

\section{INTRODUCTION}

The ambassador of Iran stood up and adjusted his tie. "We will not accept any questions from the Zionists." A ripple of laughter moved through the assembled dignitaries. The ambassador paused before continuing: "We would like to point out that there has been a $120 \%$ increase in the number of US spies caught on Iranian soil." The delegate laughed, tacitly conceding that he made up the statistic on the spot. This time, a wave of laughter rolled through the assembly. When this had subsided, the Syrian delegate stood up, offering $\$ 500$ million of assistance to the Iranians to recover from the accident

(C) Jason Dittmer

This is an Open Access article distributed under the terms of the Creative Commons Attribution License (http://creativecommons.org/licenses/by/3.0/), which permits unrestricted use, distribution, and reproduction in any medium, provided the original work is properly cited. The moral rights of the named author(s) have been asserted.

Address correspondence to Jason Dittmer, Department of Geography, University College London, Pearson Building, Gower Street, London, WC1E 6BT, UK. E-mail: j.dittmer@ucl.ac.uk 
at their nuclear site: "The continued suffering of the Iranian people cannot go on." Inexplicably, the laughter returns, growing as first the French ambassador pointed out that Syria has problems of its own [the uprising of 2011-2012] and then as the US ambassador argued that the offer of aid was really an attempt to squirrel the Assad regime's money out of the country. If this seems an unlikely scenario to be unfolding at the United Nations given its jokey tone, it is; instead I watched it occur across the ocean in a London classroom with college students playing the parts of the assembled UN delegates as part of my ethnography of Model United Nations. Created in the wake of the First World War, Model United Nations (henceforth MUN - formerly Model League of Nations ${ }^{1}$ ) is an educational simulation that students play in thirty-five countries, primarily but not exclusively in Europe and North America. The simulation is promoted by a range of actors, from the United Nations itself ${ }^{2}$ to the World Federation of United Nations Associations ${ }^{3}$ and similar simulations are promoted by regional organisations such as NATO and the European Union. ${ }^{4}$ Students can start doing MUN while in middle school, and continue through college and graduate school. Four hundred thousand students per year participate in MUN conferences ${ }^{5}$; some of them are doing MUN for course credit, while others do it as an extracurricular activity.

MUN is a role-playing simulation in which students take on the role of various state ambassadors to the United Nations. An MUN conference usually includes several concurrent committee sessions based on 'real' MUN committees. Schools are each assigned a country (or more than one) for whom they must field delegates to the various UN committees. Of course, no conference is necessary and MUN can be used as an in-class form of problem-based learning. Regardless of the size of the simulation and the experience of its players, delegates use these sessions to role play and produce resolutions that address the problems on the committee agenda. They do this by engaging in formal debate, utilising parliamentary procedure to structure the diplomatic encounter and occasionally breaking into moderated and unmoderated caucuses (a relatively informal discussion in which the chair calls on people, and a completely unstructured informal discussion with no rules, respectively). "Whether formal debate, informal debate, or caucusing, students are challenged to select and organize information about their country with great care and attention to detail. Their success in promoting their country's interests ultimately depends on their ability to select, organize, and convey information clearly and persuasively." ${ }^{\prime 6}$ Learning outcomes include not only increased knowledge of global affairs but also "enhanced . . interpersonal, public speaking and debating/negotiating skills". ${ }^{7}$ It is therefore in this context that the opening anecdote must be considered; although MUN strives to reproduce the diplomacy in the United Nations, it is embodied through students who are not only arguably operating in an environment with lower stakes, but who also bring a whole different set of assumptions, 
desires, and aims to the simulation as a result of their age, education, and national identities.

However, this is not an article about the pedagogy of geopolitics. Rather, it sees MUN as a way of engaging with students' geopolitical experiences. Intriguingly, MUN offers not only the opportunity to observe a great number of students 'talking geopolitics' but offers an educational context in which subjectivities are purposely being reshaped through students' participation in assemblage. The concept of assemblage draws from Deleuzean notions of the world as constantly becoming, with each participating body, object, and discourse enrolled in an assemblage simultaneously achieving greater coagency with all the other parts of the assemblage and also being reworked by the affective experience of participation. ${ }^{8}$ Bodies, objects, and discourses can be embedded in several assemblages at once, and can themselves be the result of processes of assemblage themselves. Therefore geopolitics can be approached through the tracing of affective connections among the elements of geopolitical assemblages. If the MUN simulation is understood as an assemblage, emergent from the active participation of role players with material objects such as placards (for being identified/called on), laptops (for writing resolutions), and so on, then their embodied participation in the assemblage can be understood as productive of affects, attitudes, and memories that shape future geopolitical action.?

In other words, MUN is not a 'faux' diplomacy; rather it is a virtual one with effects on actual geopolitics through its reproduction of a particular state-centric liberal order and an associated core-periphery structure inherited from colonialism. ${ }^{10}$ In game studies, a space such as an MUN simulation is known as the 'magic circle', in which the game's rules and player identities purportedly replace those of everyday life. ${ }^{11}$ However, it is well described in the literature that the 'magic circle' is not a separate space, but rather one that is highly permeable. ${ }^{12}$ For instance, in the case of MUN students' bodies move back and forth from the 'magic circle' to the 'real world', carrying the lessons and affective experiences of gameplay into 'actual' politics. Therefore, MUN is itself a component of the inter-state system's assemblage, a fact demonstrated by the UN's active promotion of these simulations around the world. Nevertheless, MUN also offers the potential to upset those structures through its experimentalism and its relative openness to change (in contrast to the 'real' world of geopolitics and diplomacy). Although the magic circle is highly permeable, it nevertheless allows for the suspension of many actual political limitations to thought and action, allowing for new modes of thought and action to emerge within gameplay. These new modes of being can be carried back into actual politics. Such new modes of being can be, but of course in most cases will not be, potentially revolutionary. Thus, the virtual diplomacy of MUN can work to upend long-standing patterns and gridlocks within actual diplomacy, if not through the direct importation of policies hashed out in university backrooms (a highly unlikely prospect) then 
through the direct importation of diplomatic professionals who have been shaped by the experience of gameplay in their past.

This article considers MUN from the perspective of assemblage theory because it provides a coherent basis for considering a popular geopolitics that incorporates discourses of diplomacy, a horizontal, translocal theorisation of scale that is congruent with the concerns of feminist geopolitics, and the possibility of embodied affects and materialities such as those offered by nonrepresentational theory. ${ }^{13}$ For these reasons and more assemblage theory has become a key way of thinking through international relations, the sociology of nationalism, and other topics central to geopolitics. ${ }^{14}$ Having explained what MUN is, why it matters, and with what theoretical lens it will be considered, this article now turns to a review of the nascent literature on humour and geopolitics, in which I argue that greater attention should be paid to the geopolitics of humour as affective experience. Given the importance of assemblage to geopolitics, and the importance of affect to the constitution of assemblages, this paper turns to an analysis of affective relations among the participants in MUN simulations, with a particular focus on the everyday role of humour in constituting geopolitical assemblages. Following that, a brief discussion of methodology will precede an empirical examination of humour in both traditional MUN simulations and the related simulation popularly known as Crisis. Finally, the implications of this research for the literature will be outlined, primarily the role of humour in sparking lateral, experimental thought and therefore in producing new geopolitical assemblages.

\section{GEOPOLITICS AND HUMOUR}

Popular Geopolitics, Satire, and Irony

Popular geopolitics has only recently addressed humour. Nevertheless, a few common threads have emerged that allow for some generalisations. First, perhaps not surprisingly given the emphasis of popular geopolitics on processes of mediation, the humour that has been considered has been mass-mediated humour. ${ }^{15}$ The medium of humour receiving most of this attention is the political cartoon. Both Dodds and Hammett have analysed cartoons in particular contexts to consider the ways in which political cartoons serve to undermine geopolitical commonsense in a given place and time. Dodds's work on this topic spans two decades, with a particular emphasis on the work of Guardian cartoonist Steve Bell. ${ }^{16}$ His analysis of Bell's work from the Falkland Islands campaign to the 'War on Terror' enunciates an interest in the visuality of cartoons as a space of critique, enabling anti-realist representations of geopolitical actors, events, and places that are politically potent. Juxtaposing Dodds's work with Ó Tuathail's work on the visuality of Maggie O'Kane's reporting is instructive ${ }^{17}$; Ó Tuathail argues that 
politically committed reporting employs a grounded vision of geopolitics that remains politically committed to populations, bodies, and justice. This 'anti-geopolitical eye' can be contrasted with the abstract, disembodied topdown vision that is traditionally associated with geopolitics. Bell's cartoons, although generally written without first-hand experience of the distant places in which the Falklands War and 'War on Terror' unfolded, are nevertheless politically committed to these same values and use humour to perform the useful geopolitical manoeuvre of showing how the foreign and domestic are folded into one another.

Hammett's work transports these concepts to new contexts; namely Southern Africa. His work addresses the role of political cartoons as active interventions in contemporary politics, as his story of the controversy surrounding South African cartoonist Zapiro's criticism of President Zuma attests. ${ }^{18}$ Similarly, Ridanpää has used the Jyllands-Posten cartoon incident (in which the publication of cartoon images of Muhammad in a small Danish newspaper sparked an international incident) as a starting point for discussing a second-order controversy in Finland caused by a small newspaper's cartoon about the Jyllands-Posten controversy. ${ }^{19}$ In both Hammond's and Ridanpää's cases, the cartoons are explored as phenomena that mark out the limits of acceptable debate in various national contexts.

Another medium that has received particular attention with regard to geopolitical humour is television. The ascendance of The Daily Show and The Colbert Report has sparked interest in the ways in which geopolitical attitudes are formed through humour, ${ }^{20}$ with both shows spoofing well-established television genres associated with the conveyance of political news and opinion. This has sparked moral panic about the forging of political subjectivities through humour among many of those not 'in on the joke', ${ }^{21}$ however the belief in the geopolitical efficacy of humour in this vein is demonstrated by the efforts of the US government (through its Voice of America network) to produce and distribute Parazit, a clone of The Daily Show aimed at undermining the authority of the Iranian regime. ${ }^{22}$

The preceding indicates a second thread within this literature on popular geopolitics and humour: an emphasis on satire and irony. This is not unlinked to the aforementioned emphasis on political cartoons and television fake-news programmes, as satire and irony dominate both forms. Satire can be defined as a genre of humour as attacking "specific individuals or institutions or happenings". ${ }^{23}$ Hammett's work includes another clear demonstration of satire and its power: a deck of cards (produced anonymously) that portrays various Zimbabwean political leaders as snakes. "The Guide to Dangerous Snakes in Zimbabwe uses animalization to deterritorialise and dehumanise senior figures by transmogrifying them into fictional snakes. Certain of these images are intended to provoke laughter, while others are orientated towards eliciting unlaughter." ${ }^{24}$ The cards' power comes from their juxtaposition of these serpentine portraits with images of everyday life in 
Zimbabwe in all its precariousness, effectively puncturing the legitimacy of the regime. Irony, by contrast, refers to a mode of humour that requires "the comprehending of words in the opposite way from that in which they are articulated". 25

Irony is most obviously found in one of the examples found in Dodds and Kirby's work, Stephen Colbert's stand-up routine at the White House Correspondents' Dinner. ${ }^{26}$ There, Colbert deployed a double-ness of language, saying things that sounded like praise of then-President Bush but were interpreted by all present as harsh, excoriating criticism. Similarly, Kuus has turned our attention to irony in the subtle resistance of Estonians to NATO expansion, as evidenced by newspaper columnists and cartoonists. ${ }^{27}$ Her invocation of Švejkism refers to a Central European literary trope of absurd, ironic, obedience carried out with subversive intent. Švejk is a comic character, but the effects of his ineptitude are real.

Satire and irony have been very prevalent in the literature because they enable us to think about resistance to hegemony, a key theme of the project of critical geopolitics. Similarly, the emphasis in popular geopolitics on 'large' media events such as Hollywood film and newspapers' political cartoons reflects this notion of power as resultant from the hegemonic messages of mass media and the ability of the Left to stage equally large anti-geopolitical spectacles. However, political geographers have recently embraced an understanding of power as diffuse, entangled and relational that undercuts this binary of domination and resistance. ${ }^{28}$ In this paper I seek to enunciate a popular geopolitics of humour that de-emphasises highly mediated satire and irony, in part because it is only a small portion of the humour that is geopolitical, but also because there is little empirical evidence that such antigeopolitical humour actually re-shapes geopolitical attitudes. Rather, people find things funny (or not) in connection with their already-existing political attitudes. Further, it has been found that humour lowers the level of critical attention given to a text, and therefore discounts its political significance. ${ }^{29}$

Given this ambivalence in the literature, it may be more fruitful to consider the role of affect in geopolitical humour. Affect has been defined as "a transpersonal capacity which a body has to be affected (through an affection) and to affect (as the result of modifications)".$^{30}$ Therefore, affect is the relational connections among participants in an assemblage, literally the capacity of a body or object to engage with, and be engaged by, the world around it. ${ }^{31}$ Indeed, the negativity of much (but not all) highly mediated satire with regard to politics and politicians can be understood as producing an affective predisposition among participants in the politico-cultural-media assemblage that is detrimental to the creation of a productive progressive (geo)politics: formal politics is viscerally understood to be bankrupt and not worth engagement, except as entertainment. This then requires academic attention to the ways in which affects can instead be cultivated to enable transpersonal geopolitical action. 


\section{Theorising Humour and Laughter}

Macpherson's approach to humour and laughter "attends to both conscious reflective strategies and the unconscious, irrational, embodied, and intuitive elements at play in any event of laughter." ${ }^{32}$ In this, Macpherson identifies a heuristic distinction between humour and laughter, with humour linked to cognitive processes and language (of some sort) and laughter an embodied action which may or may not be derived from humor. Therefore, we might crudely map humour onto the world of the discursive and laughter onto the world of the affective. This is not absolute, as humour and laughter are often intertwined. Laughter is (affectively) contagious, and it is easier to be deemed humorous in an environment in which people are predisposed to laugh by already existent laughter (as any stand-up comedian will tell you). Nevertheless, this heuristic is useful for illustrating how humour and laughter can work together to produce an assemblage out of bodies that were previously not linked together. ${ }^{33}$ Auslander takes up the production of such assemblages by noting how critics of stand-up comedy assess a performer by his or her ability to produce a sense of unity among the performer and audience. At issue is 'the 'energy' that supposedly exists between performers and spectators in a live event, and the 'community' that live performance is often said to create between performers and spectators." 34 This is a useful approach for this research because assemblage theory points to the emergence of new collective subjects through the enmeshing of biology and culture; it therefore requires attention to both the social (humour) and the somatic (laughter). More accurately, it points to how the social and the somatic are not easily teased apart, but each feature in the other as parts of a layered subjectivity. ${ }^{35}$

Assemblage theory offers a useful framework for thinking about humour because of its assumption that assemblages are not static, but are complex and evolve over time. This resonates with another thread in the humour literature, the importance of context and local norms. As Eco describes it, humour "seems bound to its time, society, cultural anthropology." 36 Things that are funny within one assemblage may not be funny in another. However, what is lost in Eco's claim is that which Auslander highlighted: the recognition of the role of humour and laughter in co-constituting communities. Humour and laughter have the potential to remake subjectivities in the production of new assemblages. Not only does the social practice of laughter in groups change the affective dynamic among those people in the moment, but it tinges affect-imbued memories of that moment that become part of a collective reservoir to be called upon later. In other words, humour is not merely about temporary coalitions, it is about collective predispositions held in reserve for a later date.

Humor has been theorised in a range of ways in the social sciences. In this section, I have been less concerned with identifying a particular 
theory as 'correct' than I am with theorising the role of humour. Rather, in the empirical portion of this paper I will draw on several frameworks to deal with specific instances of humour in MUN. As Meyer writes, "Several major theories claim to comprehensively explain how humor originates in the minds of those experiencing it. ... Humor has been claimed to emerge in three basic ways in human thought: through perceptions of relief, incongruity, and superiority." 37 Rather than seeing any particular theory of humour as explanatory, I see them as heuristic categories to which humorous moments can be allocated.

The superiority approach has been considered in geopolitics in the past, particularly in the work of Colin Flint (although he did not label it as such). Writing in the context of an emerging post-Cold War globalised order (prior to 9/11), Flint noted that one of the responses to global inequality has to be laughter:

The geopolitics that I envision is more hollow and self-serving. It is the laughter of the winners who are arrogant about their position in the world economy.... It is a process of laughing at oneself to accommodate other core practices rather than providing conciliation between competing world-views. It is an arrogant laugh that will maintain division. ${ }^{38}$

While Flint emphasises the division that superiority humour reproduces, that is of course also a process through which the 'self' unifies. Superiority approaches, when found in this case study, tend to relate to the socioeconomic composition of the British foreign policy establishment, University College London, and the Model United Nations Society (more on this later). This is also true of relief approaches, to which I now turn.

If Flint's laughter is associated with the inequality of geopolitics, he posits forgetting as its obverse: a rejection of globalisation and the present as-it-is. "It is a geopolitics of forgetting [in that it] relates to social groups who are either excluded from (or forgotten by) core processes or are concerned about the onslaught of materialism." 39 This has links to relief theory, in that the laughter of relief theory is an attempt to deal with a return of the repressed. Given this paper's theoretical orientation, I am here not considering relief theory in its original Freudian sense, but rather reinterpreting its laughter as an affect produced by a surplus or sudden surge of intensities within and among social bodies. Laughter in this relief theory is an escape valve for affects of tension and discomfort that are associated with questioning the contemporary geopolitical order, an inevitable event in any proper MUN conference.

Incongruity theory also appears relatively often in this research. Of particular interest is the incongruity noted by Bergson: "in a single combination, the illusion of life and the distinct impression of a mechanical arrangement." 40 This is particularly relevant to MUN because of the way in 
which formalisation of debate is heightened in diplomacy to avoid conflict. This provides numerous opportunities for humour on the basis of a human being acting as a mouthpiece for a foreign policy apparatus.

Linking all of the above is the theory advocated by Purcell, Brown, and Gokmen: disposition theory. Disposition theory is a critical perspective here that illustrates how the above frameworks are universalising, lack testable definition, and non-falsifiable. Disposition theory posits that people find things humorous depending on their own "affiliation, but [also] on whether one holds a positive or negative attitude, or disposition, toward the object of humor." ${ }^{41}$ In effect, disposition theory offers a way of explaining why sometimes things that fit the above theories are not funny. This aspect most clearly links with the contextual dimensions of humour, through which assemblages produce/are produced by communities. While each MUN simulation is its own assemblage, it is also true that the wider MUN community can also be understood as an assemblage. Each of these assemblages can be understood to develop its own 'joking culture', operating at different temporalities. Joking culture refers to "a set of repeated humorous and joking references. Over time this comic discourse comes to characterize the group to its members and can subsequently be used to identify the group. The joking becomes historicized." ${ }^{2}$ The specific dynamics of a single MUN conference's joking culture can develop within several hours, drawing on the existent joking cultures of the various MUN teams or societies that compose it, each of which develops either over months or years. Arguably, MUN itself has a broad joking culture that has developed over several decades. As one interviewee put it, "There is a very specialist humor. There is scope for geeky, quite dry wit." It is within these overlapping joking cultures that the specific instances of superiority, relief, and incongruity humor are actualised and rendered meaningful (or not).

\section{METHODOLOGY}

This research is associated with efforts to reconsider the way in which popular geopolitics has traditionally been approached. Typically popular geopolitics has been considered via an analysis of media, with its effects on audiences' subjectivities assumed rather than demonstrated. However, recent developments in audience studies, feminist geopolitics, and nonrepresentational theory offer the possibility of examining geopolitics in an everyday context, a research agenda that has been dubbed popular geopolitics 2.0. ${ }^{43}$

These research findings are based on observation of the UCL MUN Society during the 2011-2012 school year. I am not affiliated with the team in any way, but sat in on their weekly two-hour training sessions as an observer. These training sessions included both classroom-style learning as well as 
'practice' MUN simulations. I also attended two MUN conferences at which the Society fielded delegations (in November 2011 and February 2012), where I again served as a passive observer. These conferences last three days each, including opening and closing ceremonies. This ethnographic engagement was supplemented by interviews with five members of the society in officer positions; their positions as officers are not particularly relevant to these findings, but their extensive experience with MUN is (some of them had done MUN only at university; others had participated in secondary school as well).

Use of research methods such as these is not entirely new to geopolitics, but the methodological shift with which this paper aligns itself is relatively new. While critical geopolitics has long dwelled in discourse analysis, ethnographic methods such as observation and interviews have remained relatively uncommon until recent times. ${ }^{44}$ "Ethnographic observations of, and interactions with, others highlight how bodies interact, meld, and constitute social spaces, and thereby create inclusions and exclusions." ${ }^{25}$ Perhaps the closest parallel to this project methodologically is Martin Müller's ethnography of students at the Moscow State Institute of International Relations, the 'Georgetown' of the Russian foreign policy establishment. ${ }^{46}$ This research shares Müller's interest in the pedagogy of geopolitics and its role in the production of subjectivities, as well as his interest in embodied practices. As such, it is worth taking a moment to consider the specific bodies involved in this research. They are far from uniform, although they share some similarities. The students engaged in MUN simulation were all of 'traditional' university age, but were differently marked in terms of sex and skin colour. Here I follow Colls's recent suggestion that people working through non-representational theory consider the differentiated subject as "the provisional coming together of a range of forces that are material, affectual, temporal, social, political, economic, technological and so on." ${ }^{47}$ Given this framing of the adolescent or post-adolescent body, ${ }^{48}$ I see the deployment of humour in MUN as a cultural phenomenon that regulates the various identities that inform the assemblage, ${ }^{49}$ as well as a somatic phenomenon that is shaped by the circulation of affects through the assemblage, including both the technologies in use (laptops, smartphones) and the differentiated bodies of the players. The becoming of this sociality is always in flux, but nevertheless can be understood to temporarily stabilise in particular constellations of behaviour and interaction that were identified earlier as 'joking cultures'. Ethnography allowed access to the everyday workings of the 'joking culture' of MUN.

It should be noted that this research came about rather serendipitously. My interest in humour and MUN grew out of my initial observations, which were largely centred on geopolitical imaginations and more 'traditional' aspects of geopolitics. However, my attention was soon caught by the laughter that seemed to emerge and circulate through the training or conference 
space. I was reminded of the nascent literature on humour and geopolitics that has been unfolding in this journal and elsewhere and soon committed myself to the empirical collection of humour, as signalled by laughter in the training or conference space. As such, it would be misleading to imply that this project was carefully constructed and intentional; rather, it has been a pleasant discovery made in the midst of other research. With this confession, I turn to my findings.

\section{HUMOUR AND SIMULATION}

These findings are broken down by the type of simulation; most of my research was centred on MUN proper, although I also spent some time watching preparation for, and participation in, an event called Crisis. I will detail the distinction below. It is worth stating that in my year of observation I rarely saw anything but good-natured humour. That is to say, the UCL MUN Society was a remarkably affable and kind group and I rarely if ever saw humour deployed with intentional cruelty. Nevertheless, as the above brief survey of humour reveals, a great deal of humour is based on the identification of an object to be made fun of. I am interested in the larger patterns of what is revealed by such humour rather than on the role of particular individuals within the assemblage. Consequently, I have anonymised all quotes to come lest an individual be identified or embarrassed by what they have said. 'Student 1' and other such pseudonyms will refer to a range of actual students (i.e., there will be multiple Student 1s).

\section{Model United Nations}

With regard to superiority approaches, when I interviewed some of the MUN veterans about how they choose countries to be on committees, this exchange occurred:

Student 1: "We need the bad guys. Iran gets a seat automatically on a committee. North Korea ..."

Student 2: "Israel. You need the crackpots, you need the ... partly to bring a sense of humor to it. You need someone who is going to rage against the West and God knows what else. People who will dress up. The Vatican is quite a nice one. If you're doing something on women's rights, and you have a few extra spots, you might put the Vatican in there."

This exchange indicates the way a particular identity of the Self is maintained through the humorous inclusion of the Other. This inclusion on the committee is not meant as a gesture of equality, but as a way of 
demonstrating that you are open to hearing other perspectives, safe in the knowledge that they will be performed by someone who is likely to perform the role to extremity. Rhetorical extremity, occasionally matched by sartorial extremity (In MUN, delegates are asked to dress in Western business attire or national dress. The former is infinitely more common), was mentioned by another interviewee:

Student 1: "I think when some people stick to certain policies and then extrapolate them hugely, that always amuses me."

$M e:$ "Can you give an example?"

Student 1: "In Human Rights Committee, we had the Holy See [Vatican City]. And he stood up and he was wearing his cross and his [Roman] collar, and he said that in order to eradicate FGM [female genital mutilation] they should send Crusades to Africa, convert everyone to Christianity, which would automatically make FGM illegal, and everyone would be okay."

$M e$ : "So it's the extremity of the position?"

Student 1: "Absolutely. For someone to stand up and say that, and then for everyone else to say 'sit down' [laughs] is quite amusing because he is sticking to his role."

This quote, combined with the preceding, illustrates how the Vatican is singled out as a deviant actor within MUN. As argued elsewhere by Agnew, ${ }^{50}$ the Vatican's status as a theocratic actor marks it as Other and therefore subject to being the object of jokes. Implicit is the notion that these states' policies are already extreme; in the entire year I never saw a delegate for Canada or the UK try to be funny by being overly moderate and rational.

A sense of economic superiority often suffused the humour of the room; for instance, delegates representing states from the Global South often joked about their relative poverty. For example, I witnessed these delegates asking for foreign aid in order to implement resolutions that had just been passed. Similarly, I witnessed a delegate from Qatar offering Libyans displaced by the civil war (with which this particular simulation was concurrent) unpaid labour in work camps (jokingly referred to as 'internships'). Of course, as Purcell, Brown, and Gokmen argue, superiority approaches to humour depend on the disposition of the audience. Superiority approaches to humour in MUN tend to be related to the position of MUNers as largely economically privileged students. Although I have no concrete statistics, in my observation the student body at UCL has a significant number of very wealthy students, many of whom come from private secondary schools. It is worth noting that while travel to MUN conferences was part-subsidised by the Society, delegations travelled as far as Vancouver to compete. The Society was roughly gender-balanced, and relatively diverse (if not tremendously so). There was a significant group of international students practicing with the Society in the first term, but by the end most had either left the Society 
or returned home. In short, the Society had a collective sense of itself as a group of knowledgeable, Western future elites. Participants both had an idea of how the world worked (inherent to MUN) and their (future) role within that. Of course, superiority humour in this context is not necessarily meant to be cruel. Ritchie notes, for example, that college students with varying political views used humour in their discussions of homelessness to "provide a low-threat means to express their nuanced views, and allow individual members of the group a means to express both disapproval of and sympathy for homeless people." 51 Superiority humour can thus be a playful way of engaging with a difficult topic that eases the discomfort of engaging with issues that are highly charged and which highlight your own privilege, especially in an simulation where students are already role playing an identity that is not their own. ${ }^{52}$ Therefore the collective sense of MUN as elite is essential not only to interpreting the humour derived from superiority (described above) but also the humour linked to relief theory (described below).

It is perhaps not surprising that when asked about humour, none of my interviewees mentioned examples of laughter that could be classified as relief laughter; often such laughter is not registered as 'funny' as the conscious self is occupied with navigating an uncomfortable social situation. This laughter therefore might be considered distinct from humour entirely, as it is primarily affective rather than discursive; however, is it perhaps best not to make such an absolute distinction. Rather, it is perhaps more useful to look at differences between the physical manifestation of relief laughter and others. In fact, my field notes for these instances use words such as "titters", "brittleness", and "edginess". Such laughter is therefore not only qualitatively different than that of superiority and incongruity, but produces a different affect, shaping the collective experience of the MUN simulation.

The incident that most epitomises relief laughter in this research (and subsequently sparked my attention to humour in MUN) occurred during a debate on the situation in Libya, after the fall of the regime but before Gaddafi was captured and executed. The general tone of debate was fairly light-hearted, as it was a training session with mostly new people and a few experienced MUNers who facilitated debate. One of the trainers appeared before the committee, role playing Gaddafi (purportedly on satellite link from an undisclosed location to threaten the committee into inaction, but in an aside this event was described as intended "for everyone's amusement"). These events within the simulation, situated within a larger geopolitical context of Western triumphalism over the fall of the Gaddafi regime, meant that the atmosphere in the room was jovial and self-assured. Humour in this context tended towards that accounted for by superiority theory. However, contrary to all this, an experienced delegate representing Syria took the floor and gave a deft (that is, clear, powerful, but lacking in bombast) criticism of the West's intervention in Libya. The response, especially by the less experienced delegates, was a round of awkward laughter. I interpret this 
event as resulting from the rapid blocking of intensities then circulating through the assemblage. These circulations, linked to superiority humour, were shunted aside by the awkward confrontation with the geopolitics of forgetting (as enunciated by Flint above). Confronting the return of the repressed, these energies emerged as laughter.

Multiple forms of laughter can of course co-exist comfortably and be difficult to tease apart. Several weeks after the above anecdote unfolded, a training session began by recapitulating the resolution writing process (a key skill in MUN). This was, however, a reiteration of material already covered, and the individualism of the writing exercise led to a low level of intensity in the room (it is probably relevant that training occurred from 6 to 8 p.m. on Wednesdays, when many had not yet eaten). After the exercise was over, to the surprise of the trainees who thought they would be leaving soon, the training officers started a formal debate on the topic of conflict minerals. This was the first incongruity, and the debate started slowly because of the lack of intensity in the room. However, soon the delegate representing Venezuela took a shot at American imperialism, apropos of nothing in particular. This was the second incongruity, and a wave of laughter swept the room. I interpret this as relief from the built-up intensity of multiple incongruities; students had been animated neither by the affect of the room nor by the topic, but the incongruous shift to familiar topic of debate provided both a spark and a release. Here relief takes the form of an influx of rhetorical energy that emerges from the comfort of playing stereotypes. The debate proceeded with the Liberian delegate contesting Venezuela's claim to speak for the Global South, and Australia making a rather aggressive defence of resource extraction in the Global South by the Global North as the "price the third world must pay for its defense". These rather snippy exchanges between delegates, each performing extreme forms of their own stereotypes, were supplemented with relief laughter, as the debate quickly turned into a general divide between the West and 'the Rest'. This laughter can be differentiated from the superiority approach because it is not about caricaturing the Other, but rather an incongruous caricature of global inequality itself. Dipping into the reservoir of energy animating global inequality debates provided surging relief from the trudging debate at the end of a long day.

The role of incongruity theory in understanding MUN humour is significant; it certainly can be associated with a larger proportion of the laughs generated than either of the other theories. A significant portion of these laughs are produced out of the juxtaposition of the rigidity of parliamentary procedure with dynamic student bodies performing in space. Bergson's notion of humour resulting from the flesh made mechanical speaks to this phenomenon. The diplomatic need to formalise interaction among sovereign states is meant to diffuse potential conflict and de-humanise the exchange. However, secondary school and college students engaging with MUN are embodied subjects performing in space, with desires and needs that exceed 
the state-centric role they are expected to play. This excess (of humanity and of formality) is incongruous and therefore funny. For instance, my interviewees relate the tale of a male student proposing marriage to the female chair of an MUN conference (they are referring to the event's YouTube video):

Student 1: "It all builds quite nicely - he says something, she replies with 'that is not in order, please ask the chair later tonight at the social,'..."

$M e$ : "Does that [humour] have to do with the fact that she sort of rolled it into the rules of procedure? There's something about being able to change the meaning of the rules, or to bureaucratize a marriage proposal?"

Student 2: "I think that's the essence of MUN though. You can't avoid the rules of procedure in an MUN. That's what makes an MUN."

Student 1: "And that becomes a point of humor in some ways. Chairs who will make you repeat a procedural vote because not everyone votes six times. I think because you're in such a situation, anyone who is witty or makes a joke ... it's true that most people who do MUN are like-minded in some way, and find the same things amusing."

The incongruity in MUN, between (for instance) the clear support by $95 \%$ of a committee for a minor procedural manoeuver (such as taking a break from debate) and the fact that parliamentary rules specify that everyone must vote for a procedural motion to pass, or between the flirtation of students and the strict focus on agenda items, produces humour.

This happens in a multitude of forms, most of which revolve around this formal/informal binary. When discussing how to debate in the very first training session, one of the training officers told the new students that "a lot of MUN is that it is quite polite and nice. What's fun is that clever people find clever ways to insult one another." Similarly, a common laugh line in MUN occurs in moments of debate when it is against the rules to make a speech, but not to ask a question of the previous speaker (known as a point of information). Frequently, this rule is circumvented by making a speech and concluding it with "don't you agree?" to great laughter and smatterings of applause from other delegates, who appreciate the ability of the speaker to deviate from the rules without actually violating them. The reverse is also funny; procedural votes are often dispensed with by committee chairs who, after a motion is seconded, ask if there are any objections: all one prankster has to do is verbally object, and that forces the committee to have a vote (in which, if the prankster wants to go a step further, they can 'forget' to vote thus causing another vote given the rules regarding procedural votes described above). Thus, incongruity works either through an excess of humanity (e.g., the marriage proposal) or through an excess of formality (e.g., over-voting). 


\section{Crisis}

Crisis refers to an activity that takes place at MUN conferences, but which differs substantially from the rest of the conference activities. Most Crisis simulations take the form of a Joint Cabinet Crisis, in which (at least) two committees are formed, each representing the Cabinet or National Security Council of a country. Individual delegates role play the actual members of that committee (e.g., the US president or chief of the Chinese army). In addition, there is a Crisis staff (usually two or three people) who feed scenario information to both committees, engineer conflict between them, and in general facilitate the committees' interaction (usually involving a flashpoint of mutual contention, such as Georgia (for US/Russia Crisis) or North Korea (for US/China Crisis). Therefore, Crisis unfolds as a debate, like MUN, about various state policy options. Nevertheless, unlike MUN, the individual players have access to their bureaucratic resources and are capable of independent action, such as gathering intelligence resources on the enemy or on their fellow Cabinet members, deploying troops, arresting internal dissidents, and so on.

Student 1: "It's essentially war games, with each committee playing against each other and the Crisis staff playing everyone else, and people inside playing against each other. 'War games' is correct in that sometimes you are playing war and moving stuff around, and it's also a euphemism like political intrigue."

As this quote implies, Crisis is about conflict, both within the cabinet and between cabinets, rather than the consensus which is the intention of MUN.

Student 1: "The ecological niche is basically nerds who like to role play and have fun. It's quite different [because of] the sort-of geopolitical elements and it's a lot more like role playing in a traditional gaming sense. ... [Crisis is] a lot more dynamic, it's very chaotic."

Student 2: "It's a mess."

Student 1: "But that's why I like it. And that quite closely maps onto real life which is messy. And I think for people who are political adrenaline junkies it's always going to be the way you are going to go. It's like a real-time strategy game but with other people to play with! ... A lot of the skills you develop in Crisis are about the political intricacies of something, and the ability to kill all your rivals and take over a country and rule it by yourself. None of which are actually relevant in ordinary MUN. So, I think in many ways Crisis is not really an evolution of normal MUN, in many ways it's not even related to normal MUN. So for instance the Crisis I did in New York was basically a game of Risk, where we talked about it and moved our pieces on the board." 
If MUN is a subculture, then Crisis is a sub-subculture. In terms of disposition theory, Crisis is unique in that because it is so demanding both in terms of the level of preparation and in its intensity (the cabinets are much smaller than MUN committees and so it is harder to hide) that there is a fairly limited pool of people who can/choose to play. This leads to a familiarity among the people on 'the circuit'. The bodies participating in the assemblage are more uniform in terms of their sex, and this shapes the way the assemblage unfolds. One female MUNer described Crisis to me thus: "There are a number of people who are quite geeky about it. And I'm sorry to say it's the boys. They know their ships, they know their planes. They know their serial codes and what date this thing is going to be completed by." Because of all these factors in the disposition of Crisis players, the style of humour can be seen to be rather distinct. In this discussion, I will refrain from running through the typology of humour found in MUN, as nearly all that discussed above is true of Crisis as well. Rather, I will emphasise what is different about humour in Crisis.

The primary source of humour in Crisis comes from the precariousness of everyone's position in any given moment. As alluded to above, the game is not simply inter-cabinet, but also intra-cabinet. Some players are spying against their own side, and others are seeking to unseat the chair of their committee (who is the president or some other chief executive) and gain the office themselves. In a training session for Crisis that I witnessed so many students were eliminated by this kind of manoeuvring that any time Crisis staff asked to speak with a delegate, she or he asked "am I dead?" Managing to eliminate a rival, either in your own cabinet or in the other cabinet, is a feat to be savoured. Even more glorious (and likely to be talked about for years to come) is to eliminate a rival in a particularly "sadistic" way:

Student 1: "People come up with interesting ways of killing people. And laugh about it. ... they will have fun coming up with the most cruel and nasty ways of getting rid of people."

$M e:$ "Like what?"

Student 2: "I was shot ten times in the face having gotten off the plane in London because I was Sarah Palin. Yeah. And pretty much that whole conference I had to survive six assassination plots. ... The specific point being that Sarah Palin had been shot in the head ten times with a shotgun, leaving time to reload. Nobody bothered to intervene..."

Of course, given the numerous axes of difference that separate most Crisis players from Sarah Palin, it would be a mistake to read the above as necessarily being misogynist. However, given the disposition of those playing Crisis, sexual humiliation is often a facet of someone's elimination. I witnessed one player be framed for child molestation and another thrown out of office for being caught with a prostitute named "Big Jiggly." 
It goes without saying that such humour is highly context-dependent. The long-standing relationships among people who play Crisis, who happen to be mostly young post-adolescent men interested in geopolitical role play, means that humour is less about incongruity, and tends further towards superiority. This means that a level of comfort is achieved with one another and common interests allow free play to humour; it is also notable that the rules regarding communication in the cabinets are far looser than in MUN, so colloquial expression is more commonplace. For instance, one interviewee told me a story about a time he was playing President Obama in a Crisis, and he bombed a terrorist camp in Libya, evoking an ultimatum from Libya: an apology, or war.

Student 1: "My reply was 'bring it on' and the entire cabinet laughed at this, because it was Libya threatening war against the US. 'Bring it on' seemed appropriate. [Sees my blank face, as my mind is linking his comment to President Bush's challenge to Iraqi insurgents in an all-too congruous way] It's something which said here doesn't sound funny, but at the time, that's incredible - the act of doing that - 'Bring it on' - the entire cabinet burst into laughter."

We have all been in that student's position, suddenly confronted with explaining why something funny in one context does not now seem funny. But that hints at the way assemblages, like individual MUN and Crisis simulations, are interesting. The affective dimensions of humour illustrate how the experience of MUN and Crisis embeds itself in memories that will be drawn on in the future to make both instinctive and rational political decisions. Those memories can lend themselves to progressive ends, such as a predilection for compromise and consensus, or lend themselves to conflict through a predisposition to strategic zero-sum conceptualisations of politics.

\section{CONCLUSIONS}

This article has attempted to think about the geopolitics of humor beyond both highly mediated contexts such as cartoons, television, and the internet, and also the traditional emphasis in popular geopolitics on satire and irony as weapons of the weak to be deployed against hegemony. These sites and emphases carry with them particular assumptions about popular geopolitics and power that may not hold. Rather, this article has sought to deal with conversational humour within a subculture devoted to geopolitical simulation.

In this article I have largely been critical of the basis for humour in both MUN and Crisis, illustrating the roots of this humour in the exteriorisation of geopolitical difference. However, other forms of humour and laughter have also been highlighted which are not dependent on someone being 
the (explicit or otherwise) butt of the joke (notably much of the humour based on incongruity). My point, however, is not to serve as the humour police. As Purcell, Brown, and Gokmen point out, disposition theory indicates that people are often willing to laugh at jokes directed at them, their ethnic group, their gender, and so on. ${ }^{53}$ We should not assume the effects of humour from the content of humour. It would therefore be a mistake to limit the power of such humour to its ability to stereotype and substantiate inequality (although it can, indeed, do that). Rather, it is worth considering the geopolitical power of humour to contribute to the constitution of assemblages. Indeed, while observing the Crisis simulation at the University of Oxford, two students walked up to the window, looked in and saw the (MUN Crisis) American National Security Council, dressed in suits, sitting behind their placards, and with a large American flag hanging in the background. One murmured something to the other, who burst into laughter as they walked away. It was a potent reminder of the role of humour in constituting assemblages, both from within and from the outside.

As John Allen argues, power is not just power over, but also power to. ${ }^{54}$ Therefore, we must consider not just the way in which 'making fun' can re-inscribe social difference within groups, but also its role in the enabling of groups to work in concert towards larger ends. As Peter Serracino-Inglott argues, "Even if it is just two people who laugh at the same joke, it is a sure sign that they have established contact with each other at a deep level. That is, in any case, a most difficult and important human achievement." ${ }^{5}$ The role of humour and laughter in constituting groups, through discourse and affect, enables an assemblage to emerge as something with more agency than the components that compose it. While MUN may seem a frivolous task, it is part of the larger assemblage of diplomacy - a context in which it is easily recognised that what can be gained through coordinated, collective labour far exceeds the effect of individual efforts. Indeed, MUN and Crisis offer opportunities for experimental thinking on topics of global importance and in venues that are unconstrained by what passes for 'political reality,' and its subcultural humour is an important part of that. The role of humour in re-configuring an assemblage, whether MUN or the larger realm of diplomacy that it simulates, is serious business. "A serious joke ... is a provocation to both parties displaying the possibility of adapting an as yet unexplored angle of approach." ${ }^{56}$ As such, it deserves continued attention from geopolitical scholars.

\section{NOTES}

1. D. McIntosh, 'The Uses and Limits of the Model United Nations in an International Relations Classroom', International Studies Perspectives 2/3 (2001) p. 270.

2. UN CyberSchoolBus, available at <http://www.un.org/cyberschoolbus/modelun/over.html>, accessed 15 Oct. 2012. 
3. WFUNA and Model UN, available at <http://www.wfuna.org/wfuna-mun>, accessed 15 Oct. 2012.

4. B. Ripley, N. Carter, and A. Grove, 'A League of our Own: Creating a Model United Nations Scrimmage Conference', Journal of Political Science Education 5/1 (2009) p. 55.

5. K. Crossley-Frolick, 'Beyond Model UN: Simulating Multi-Level, Multi-Actor Diplomacy Using the Millennium Development Goals', International Studies Perspectives 11/2 (2010) p. 187.

6. Ibid., p. 186.

7. J. Kaufman, 'Using Simulation as a Tool to Teach about International Negotiation', International Negotiation 3/1 (1998) p. 62.

8. On assemblage theory, see M. Delanda, A New Philosophy of Society: Assemblage Theory and Social Complexity (London: Continuum 2006). On assemblage and geography, see B. Braun, 'Environmental Issues: Global Natures in the Space of Assemblage', Progress in Human Geography 30/5 (2006) p. 644; B. Anderson and C. McFarlane, 'Assemblage and Geography', Area 43/2 (2011) p. 124; B. Anderson, M. Kearnes, C. McFarlane, and D. Swanton, 'On Assemblages and Geography', Dialogues in Human Geography 2/2 (2012) p. 171.

9. W. Connolly, Neuropolitics: Thinking, Culture, Speed (Minneapolis: University of Minnesota Press 2002).

10. F. McConnell, T. Moreau, and J. Dittmer, 'Mimicking state Diplomacy: The Legitimizing Strategies of Unofficial Diplomacies', Geoforum 43/4 (2012) p. 804.

11. J. Huizinga, Homo Ludens: A Study of the Play Element in Culture (Boston: Beacon 1950).

12. K. Salen and E. Zimmerman, Rules of Play: Game Design Fundamentals (London: MIT Press 2004); E. Castronova, Synthetic Worlds: The Business \& Culture of Online Games (Chicago: University of Chicago Press 2005).

13. On feminist notions of scale, see J. Sharp, 'Geography and Gender: Finding Feminist Political Geographies', Progress in Human Geography 31/3 (2007). On laughter and non-representational theory, see H. Macpherson, “I Don't Know Why They Call It the Lake District They Might as Well Call It the Rock District!" The Workings of Humour and Laughter in Research with Members of Visually Impaired Walking Groups', Environment and Planning D: Society and Space 26/6 (2008).

14. J. Puar, Terrorist Assemblages: Homonationalism in Queer Times (Durham, NC: Duke University Press 2007); E. Cudworth and S. Hobden, Posthuman International Relations (London: Zed Books 2011).

15. Purcell, Brown, and Gokmen have examined the geopolitics of Jeff Dunham's 'Achmed the Dead Terrorist' stand-up comedy routine, and while they have done so in the context of the routine's YouTube video phenomenon (therefore falling into the category of 'highly mediated'), they are primarily concerned with the processes of audiencing: how viewers of the video bring their own contextualisations to the interpretive process and how they serve to reproduce the viewing event itself by forwarding links, 'liking' the video on Facebook, and so on. In this sense they are interested in viewing humour as geopolitical agency both shaping everyday life and in which people individually participate. This work is inspirational to this project given this notion of the popular as exceeding its mass mediation but instead relying on audience power to drive the assemblage. See D. Purcell, M. Brown, and M. Gokmen, 'Achmed the Dead Terrorist and Humor in Popular Geopolitics', GeoJournal 75/4 (2010) p. 373.

16. K. Dodds, 'The 1982 Falklands War and a Critical Geopolitical Eye: Steve Bell and the If . . . Cartoons', Political Geography 15/6-7 (1996); K. Dodds, 'Steve Bell's Eye: Cartoons, Geopolitics and the Visualization of the 'War on Terror", Security Dialogue 38/2 (2007).

17. G. Ó Tuathail, 'An Anti-Geopolitical Eye? Maggie O'Kane in Bosnia, 1992-94', Gender, Place and Culture $3 / 2$ (1996).

18. D. Hammett, 'Zapiro and Zuma: A Symptom of an Emerging Constitutional Crisis in South Africa?', Political Geography 29/1 (2010).

19. J. Ridanpää, 'The Geopolitics of Humour: The Muhammed Cartoon Crisis and the Kaltio Comic Strip Episode in Finland', Geopolitics 14/4.

20. K. Dodds and P. Kirby, 'It's Not a Laughing Matter: Critical Geopolitics, Humour and Unlaughter', Geopolitics 18/1 (2013) pp. 45-59.

21. For a considered analysis of this phenomenon, see J. P. Jones, Entertaining Politics: New Political Television and Civic Culture (Lanham, MD: Rowman \& Littlefield 2004).

22. M. Semati, 'The Geopolitics of Parazit, the Iranian Televisual Sphere, and the Global Infrastructure of Political Humor', Popular Communication 10/1 (2012).

23. A. Berger, An Anatomy of Humor (Piscataway, NJ: Transaction Publishers 1999) p. 49. 
24. D. Hammett, 'Resistance, Power and Geopolitics in Zimbabwe', Area (2011) 43/2.

25. Ridanpää (note 19) p. 732.

26. Dodds and Kirby (note 20).

27. M. Kuus, 'Švejkian Geopolitics: Subversive Obedience in Central Europe', Geopolitics 13/2 (2008).

28. J. Allen, Lost Geographies of Power (Oxford: Blackwell 2003).

29. D. Young, 'The Privileged Role of the Late-Night Joke: Exploring Humor's Role in Disrupting Argument Scrutiny', Media Psychology 11/1 (2008) p. 119.

30. B. Anderson, 'Becoming and Being Hopeful: Towards a Theory of Affect', Environment and Planning D: Society and Space 24/5 (2006) p. 733 (emphasis in original).

31. S. Pile, 'Emotions and Affect in Recent Human Geography', Transactions of the Institute of British Geographers 35/1 (2010) p. 5.

32. Macpherson (note 13) pp. 1082-1083.

33. J. Meyer, 'Humor as Double-Edged Sword: Four Functions of Humor in Communication', Communication Theory 10/3 (2000) p. 310.

34. P. Auslander, Liveness: Performance in a Mediatized Culture (London: Routledge 1999) p. 2.

35. J. Protevi, Political Affect: Connecting the Social and the Somatic (Minneapolis: University of Minnesota Press 2009).

36. U. Eco, Travels in Hyperreality (London and New York: Harcourt 1986) p. 269.

37. J. Meyer (note 33) pp. 311-312.

38. C. Flint, 'The Geopolitics of Laughter and Forgetting: A World-Systems Interpretation of the Post-Modern Geopolitical Condition', Geopolitics 6/3 (2001) p. 7.

39. Ibid., p. 8.

40. H. Bergson, Laughter: An Essay on the Meaning of the Comic (Rockville, MD: Arc Manor 2008) p. 38.

41. Purcell, Brown, and Gokmen (note 15) p. 376.

42. G. Fine and M. de Soucey, 'Joking Cultures: Humor Themes as Social Regulation in Group Life', Humor 18/1 (2005) p. 2.

43. J. Dittmer and N. Gray, 'Popular Geopolitics 2.0: Towards New Methodologies of the Everyday', Geography Compass 11/4 (2010).

44. N. Megoran, 'For Ethnography in Political Geography, Experiencing and Re-Imagining Ferghana Valley Boundary Closures', Political Geography 25/6 (2006); R. Pain and S. Smith, Fear: Critical Geopolitics and Everyday Life (Aldershot: Ashgate 2008); M. Kuus, 'Policy and Geopolitics: Bounding Europe in EUrope', Annals of the Association of American Geographers 101/5 (2011).

45. A. Watson and K. Till, 'Ethnography and Participant Observation', in D. DeLyser, S. Herbert, S. Aitken, M. Crang, and L. McDowell (eds.), The SAGE Handbook of Qualitative Geography (Los Angeles, SAGE 2010) p. 122.

46. M. Müller, 'Education and the Formation of Geopolitical Subjects', International Political Sociology 5/1 (2011).

47. R. Colls, 'Feminism, Bodily Difference and Non-Representational Geographies', Transactions of the Institute of British Geographers 37/3 (2012) p. 431.

48. For a brief overview, see R. Colls and K. Hörschelmann, 'The Geographies of Children's and Young People's Bodies', Children's Geographies 7/1 (2009) p. 1.

49. M. J. Kehily and A. Nayak, "Lads and Laughter': Humour and the Production of Heterosexual Hierarchies', Gender and Education 9/1 (1997) p. 69.

50. See J. Agnew, 'Deus Vult: The Geopolitics of the Catholic Church', Geopolitics 15/1 (2010) p. 39.

51. L. D. Ritchie, "You're Lying to Jesus!" Humor and Play in a Discussion about Homelessness', Humor 24/4 (2011) p. 507.

52. On the relationship between play and identity, see T. Woodyer, 'Ludic Geographies: Not Merely

Child's Play', Geography Compass 6/6 (2012) p. 313.

53. Purcell, Brown, and Gokmen (note 15).

54. Allen (note 28).

55. P. Serracino-Inglott, 'To Joke or Not to Joke', in J. Kurbalija and H. Slavik (eds.), Language and Diplomacy (Malta: DiploProjects 2001) p. 30.

56. Ibid., p. 33. 